\title{
ON THE BRAIN WEIGHTS OF RATS DESCENDED FROM THE CROSS BETWEEN THE WILD NORWAY (MUS NORVEGICUS) AND THE DOMESTICATED ALBINO (MUS NORVEGICUS ALBINUS)
}

\author{
SHINKISHI HATAI \\ The Wistar Institute of Anatomy \\ TWO CHARTS
}

The present study was undertaken to determine the influence of the parental brain weight on that in the offspring. For this purpose wild norway rats (Mus norvegicus) were crossed with their domesticated variety, the albino rats. The main advantages in employing these animals are two: 1 ) these two forms interbreed readily in confinement (Hatai, '07) and 2) the brain weight in the Norway is considerably heavier (about 14 per cent in the adults) than that of the Albino of the same body weight or length (Donaldson and Hatai, '11). It was thought possible that the respective brain weights might be inherited as Mendelian characters and thus enable us to differentiate the Norway type from the albint type among the descendants. At the same time we encounter in such a study several drawbacks: 1) the fact that we do not possess any data by which to estimate the probable effect of domestication on the Norway rats during the experiment and 2) that we do not know the effect of close inbreeding on the weight of the brain under the changed conditions for the Norway.

The lack of these data naturally limits our interpretation of the results. Nevertheless the results thus far obtained seem to indicate rather clearly that the brain weights in the hybrids lie practically midway between those in the parents. Thus the inheritance of brain weight in this experiment appears to be an example of 'blending inheritance' and it is the object of the pressent paper to give the evidence for this conclusion. 


\section{MATERIAT}

The Norway rats here used were trapped at different points in the city of Philadelphia, while the Albinos were secured from the colony kept at The Wistar Institute. The total number of the Norway rats employed was 6 males and 4 females, and of the Albinos used, 3 were males and 9 females. With these rats 14 matings were made successfully. Although more than twice the number of rats named above were mated at the beginning of the experiment, the data for many had to be discarded on account either of the loss of parents or of the sterility of the hybrids of the $F_{1}$ generation. Only those cases in which the data on the parents as well as their offspring for the first two generations were secured, were used in the present paper. The total number of the hybrids examined was $110 \mathrm{~F}_{1}$ and $149 \mathrm{~F}_{2}$.

THE METHOD OF COMPARING THE BRAIN WEIGHTS

In comparing the brain weights in the hybrids with those in the parents, the following method was adopted. As has been already found by Donaldson ('08) with the albino rat, and by Donaldson and Hatai ('11) with the Norway rats, the brain weight varies with the body length according to a logarithmic law. Since the body lengths in the hybrids were not identical with those in the parents, a direct comparison of the observed brain weights without a due consideration of the difference in the body length was not justified. The proper adjustment was however made possible by utilizing the following formulas (for sexes combined).

For Norway rat (Donaldson and Hatai, '11).

$$
\text { Body weight }=10^{\frac{\text { Body lenoth }+165}{150^{2}}}-18
$$$$
\text { Brain weight }=0.825 \log (\text { Body weight }-4)+0.233
$$

For albino rat (Donaldson, '08) .

$$
\begin{aligned}
& \text { Body weight }=10^{\text {Body length }+134} 143(5 \\
& \text { Brain weight }=0.569 \log (\text { Body weight }-8.7)+0.554
\end{aligned}
$$


The frequency distribution of the brain weights within the litter seems to be continuous, and thus the Norway type or albino type cannot readily be differentiated. Consequently I have adopted the statistical method of taking the averages of all the rats belonging to each generation separately. At the same time I have plotted all individual brain weights in chart I in order to show the extent of the variation, as well as the relative positions held by the records belonging to the different generations.

The averages were taken for the sexes combined. This procedure affords some advantage since by this means we can deal with a larger number of rats and thus can eliminate irregularities arising from the averages of smaller data. Any disturbance which arises from the sexual difference in the brain weights is almost insignificant since such a difference amounts to less than 0.5 per cent in the albinos and about 1 per cent in the Norway rats. The formulas given above may be applied directly when the sexes are not distinguished.

\section{BRAIN WEIGHTS IN THE NORWAY AND ALBINO RATS}

In table I are given the data on the brain weights for both the norway and albino rats which have been used as parents of $F_{1}$ in the present experiment. As will be seen some rats are recorded in the table several times. This repetition was necessitated by the fact that these rats were crossed several times with different rats and thus they were counted as often as the matings were made.

Norway rat. The observed average brain weight of the Norway rats with a body length of $237 \mathrm{~mm}$. is 2.251 grams. According to the formula the Norway rat with a body length of 237 mm. should give a brain weight of 2.295 grams. Thus the observed brain weight is 1.91 per cent less than the value given by the formula. The computed brain weights for the Norways which appear in chart I were obtained by subtracting 1.91 per cent from the formula values. 
Albino rat. In the albino rat with a body length of $194 \mathrm{~mm}$. we obtain an observed average brain weight of 1.740 grams. The formula gives however 1.827 grams for the body length of $194 \mathrm{~mm}$., thus the observed brain weight is 4.65 per cent less than the value given by the formula. The computed brain weight for the Albino which appear in chart I were obtained by subtracting 4.65 per cent from the values given by the formula. These computed values for the Norway and albino rats were taken as the basis for estimating the positions which the brain weights of the hybrids occupy.

\section{TABLE 1}

Showing the data on the body lenglh and brain weights in both the norway and albino rat used as parents

Norway M. $\times$ albino $F .=9$ cases

Norway F. $\times$ albino M. $=5$ cases

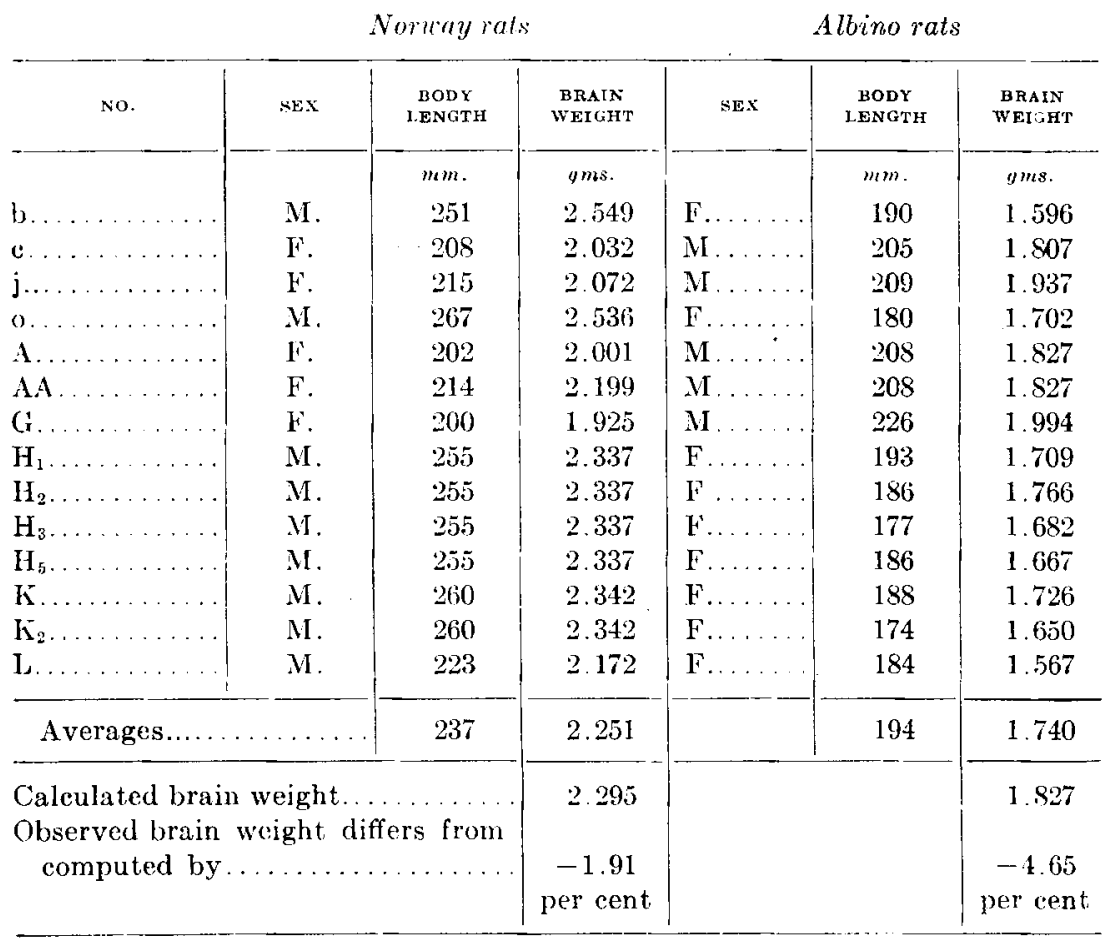


BRAIN WEIGH'TS IN THE FIRST HYBRID GHNERATION RATS (F $\left.F_{1}\right)$

From the correlation table (table 2 ) the average brain weights corresponding to the different body lengths were calculated for $F_{1}$ and these are given in chart 1 together with the corresponding

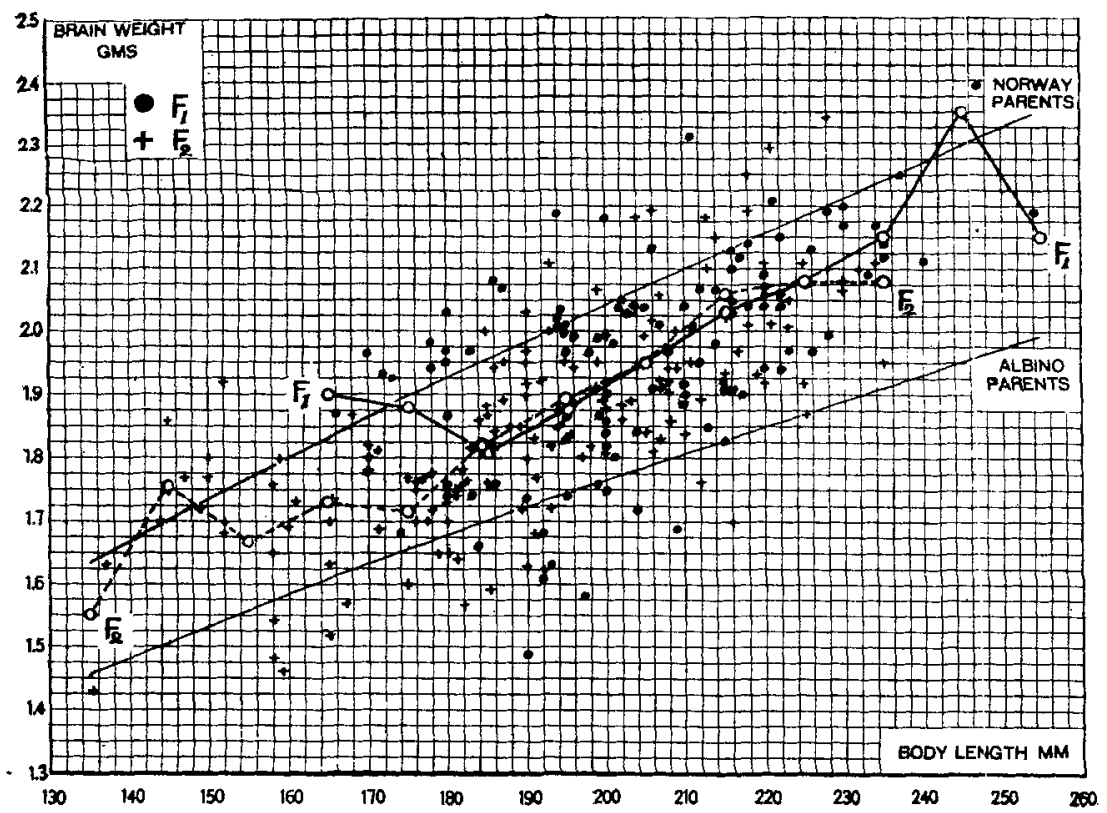

Chart 1

Showing the computed brain weights in the Norways and Albinos used as parents. Also the average brain weights for the $F_{1}$ and $F_{2}$ generations iogether with all the individual brain weights belonging to these hybrid rats.

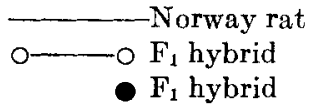

$$
\begin{array}{r}
- \text { Albino rat } \\
-0 F_{2} \text { hybrid } \\
+F_{2} \text { hybrid }
\end{array}
$$

individual brain weights. It is to be remembered that all the rats of this generation are gray in color. We note from the chart that with the exception of both ends of the graph where the number of observations is small, the average values give a very smooth graph and occupy practically intermediate positions between the brain weights given by the norway and albino parents. Furthermore, from the distribution of individual brain 
weights (chart 1) we do not see any indication of discontinuity; in other words the distribution of the brain weights is concentrated round the average values instead of being concentrated about the Norway and Albino mean values respectively. This indicates that so far as the present data are concerned the brain weights in the first hybrid generation are intermediate between those of the parents. When the continuous character of the distribution of the brain weights is compared with calculated values according to the law of probability by the formula

$$
y=26.89 e^{-0.1877 x^{2}}
$$

we note the close agreement between observation and calculation which justifies the statement made above. (Chart 2. $F_{1}$.)

TABIL 2

\begin{tabular}{|c|c|c|c|c|c|c|c|c|c|c|c|c|}
\hline$F_{1}$ GENERATION & & & & BHA & $\mathrm{N}$ WE & GHT & iMs. & & & & | 菣 & \\
\hline Body length & 亲 & 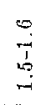 & $\stackrel{\vec{I}}{\mathfrak{d}}$ & $\underset{-1}{+}$ & \begin{tabular}{|}
0 \\
- \\
$\infty$ \\
- \\
-
\end{tabular} & $\begin{array}{l}0 \\
\text { ì } \\
\text { d. } \\
\text { - }\end{array}$ & $\begin{array}{l}\tilde{a} \\
\text { ôे } \\
\text { sj }\end{array}$ & $\underset{a}{\vec{i}}$ & 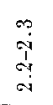 & 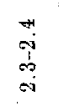 & 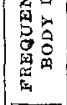 & 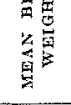 \\
\hline $\begin{array}{c}m m \\
160-170 \\
170-180 \\
180-190 \\
190-200 \\
200-210 \\
210-220 \\
220-230 \\
230-240 \\
240-250 \\
250-260\end{array}$ & 1 & 1 & $\begin{array}{l}1 \\
1 \\
3 \\
1\end{array}$ & $\begin{array}{l}2 \\
3 \\
3 \\
2\end{array}$ & $\begin{array}{l}1 \\
2 \\
1 \\
7 \\
3 \\
3\end{array}$ & $\begin{array}{l}1 \\
5 \\
1 \\
5 \\
5 \\
6 \\
4\end{array}$ & $\begin{array}{r}1 \\
2 \\
4 \\
7 \\
11 \\
2 \\
1\end{array}$ & $\begin{array}{l}2 \\
1 \\
3 \\
5 \\
4 \\
1\end{array}$ & $\begin{array}{l}1 \\
1\end{array}$ & 1 & \begin{tabular}{|r|}
2 \\
11 \\
9 \\
25 \\
19 \\
24 \\
12 \\
6 \\
1 \\
1
\end{tabular} & $\begin{array}{l}1.90 \\
1.88 \\
1.81 \\
1.88 \\
1.95 \\
2.03 \\
2.08 \\
2.15 \\
2.35 \\
2.15\end{array}$ \\
\hline $\begin{array}{l}\text { Frequency } \\
\text { brain weight. }\end{array}$ & 1 & 1 & 6 & 10 & 17 & 27 & 28 & 16 & 2 & 2 & 110 & \\
\hline
\end{tabular}

BRAIN WEIGHTS IN THE SECOND HYBRID GENERATION RATS (F.)

In chart 1 the average brain weights for corresponding body length as well as the individual brain weights for $F_{2}$ are recorded. The averages were obtained from the correlation table (table 3 ). As is shown in the chart the average brain weights in the second hybrid generation are practically identical with those in the first 
TABLE 3

\begin{tabular}{|c|c|c|c|c|c|c|c|c|c|c|c|c|}
\hline$F_{2}$ GENERATION & \multicolumn{10}{|c|}{ BRAIN WEIGHT GMS. } & \multirow{2}{*}{ 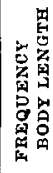 } & \multirow{2}{*}{ 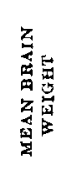 } \\
\hline Body length & 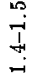 & - & $\stackrel{5}{0}$ & $\stackrel{\infty}{i}$ & $\stackrel{\infty}{+}$ & @i & $\vec{i}$ & $\frac{i}{i}$ & $\begin{array}{c}\text { âj } \\
\text { aे } \\
\text { ai }\end{array}$ & $\begin{array}{l}\vec{H} \\
i \\
0 \\
i \\
i\end{array}$ & & \\
\hline \multicolumn{13}{|l|}{$m m$. } \\
\hline $130-140$ & \multirow[t]{2}{*}{1} & & \multirow[t]{2}{*}{1} & & & & & & & & 2 & 1.55 \\
\hline $140-150$ & & & & 6 & 1 & & & & & & 7 & 1.76 \\
\hline $150-160$ & \multirow[t]{9}{*}{2} & 1 & 3 & 2 & 1 & 1 & & & & & 10 & 1.67 \\
\hline $160-170$ & & 2 & 1 & 5 & 3 & & & & & & 11 & 1.73 \\
\hline $170-180$ & & 1 & 4 & 9 & 1 & & & & & & 15 & 1.72 \\
\hline $180-190$ & & 2 & 2 & 8 & 8 & 7 & 1 & & & & 28 & 1.82 \\
\hline $190-200$ & & & 2 & 2 & 11 & 8 & 2 & 1 & & & 26 & 1.89 \\
\hline $200-210$ & & & & & 8 & 7 & 3 & 2 & & & 20 & 1.95 \\
\hline $210 \cdots 220$ & & & 1 & 1 & 1 & 5 & 2 & 5 & 1 & & 16 & 2.06 \\
\hline $220-230$ & & & & & 1 & 1 & 6 & 1 & 1 & 1 & 11 & 2.08 \\
\hline $230-240$ & & & & & & 1 & & 2 & & & 3 & 2.08 \\
\hline \multirow{2}{*}{$\begin{array}{l}\text { Frequency } \\
\text { brain weight. }\end{array}$} & \multirow[b]{2}{*}{3} & \multirow[b]{2}{*}{6} & \multirow[b]{2}{*}{14} & \multirow[b]{2}{*}{33} & \multirow[b]{2}{*}{35} & \multirow[b]{2}{*}{30} & \multirow[b]{2}{*}{14} & & & \multirow{2}{*}{\multicolumn{2}{|c|}{1149}} & \\
\hline & & & & & & & & 11 & 2 & & & \\
\hline
\end{tabular}

hybrid generation and thus the brain weights occupy an intermediate position between the values given by the norway and albino rats and are like those of their immediate ancestors.

The distribution of the individual brain weights in $F_{2}$ rats is similar to that of the $F_{1}$ rats and the concentration is greatest round the mean value. The frequency distribution of the brain weights in $\mathrm{F}_{2}$ rats is best shown in chart 2 where observed frequencies are compared with those computed by the following formula for the normal probability

$$
\begin{aligned}
& y=34.41 e^{-0.1725 x^{2}} \\
& \text { FREQUENCY CURVES }
\end{aligned}
$$

Particular interest attaches to the frequency curves (chart 2) given by the brain weights in both the $F_{1}$ and $F_{2}$ series. The observed frequency distribution. is closely represented by the normal probability curve; that is the distribution is symmetrical around the mean brain weight. I have shown in a previous paper (Hatai, '11) that the symmetrical distribution of the 
characters may arise when the two parental characters blend together with equal potency and the limiting case of such distribution leads to the normal probability curve. The brain weights here investigated may thus be taken as a good example of the limiting case of the formula of the blending inheritance, where dominance is absent.

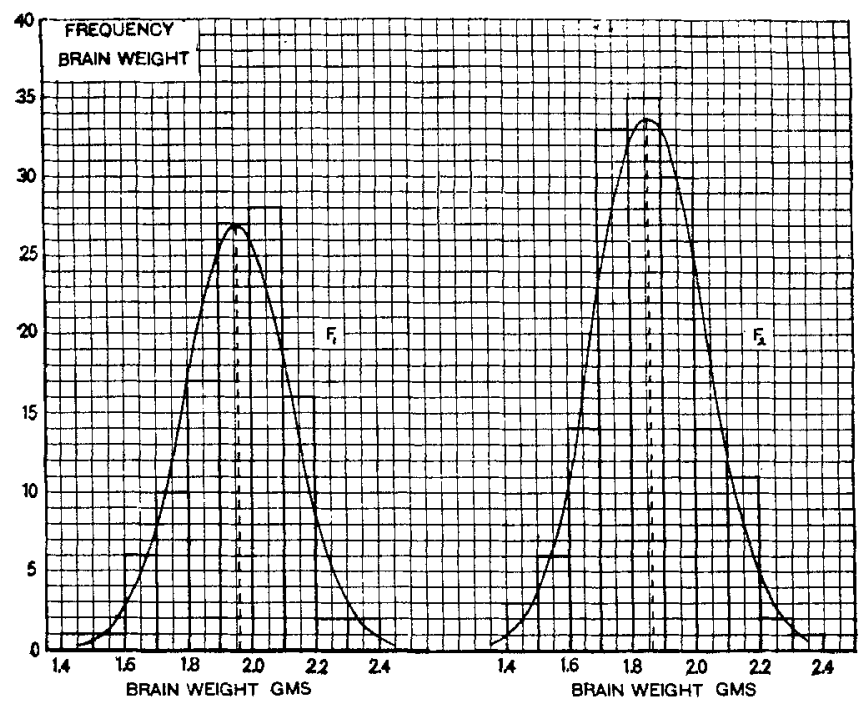

Chart 2

\section{COAT COLOR AND BRAIN WEIGHT}

It may be added that in the $\mathrm{F}_{2}$ generation we usually obtain five varieties of coat color in rats; self gray, black, gray piebald, black piebald and albino (see Bateson, '09). In our experiment the mortality was somewhat large and in as much as the inheritance of the coat color was not the object of the present experiment, the census of the coat colors of the dead rats was unfortunately not taken. We find however from an examination of the final records 42 albino and 107 pigmented rats, or a proportion of 1 albino to 2.6 pigmented, thus coming very close 
to the expected number of one Albino to three pigmented. I have tried to determine whether or not the brain weight varies systematically with coat color. The following table gives the results of examination.

\begin{tabular}{|c|c|c|c|c|}
\hline . & BODY LENGTH & BRAIN WEIGHT & $\begin{array}{c}\text { CALCULATED BRAIN } \\
\text { WEIGHTS INTERME- } \\
\text { DIATE BETWEEN } \\
\text { PARENT NORWAY } \\
\text { AND PARENT } \\
\text { ALBINO }\end{array}$ & $\begin{array}{l}\text { DEVIATION FROM } \\
\text { CALCULATED } \\
\text { INTERMEDIATE } \\
\text { VALUES }\end{array}$ \\
\hline $\begin{array}{l}\text { Pigmented coat. } \\
\text { White........... }\end{array}$ & $\begin{array}{l}m m \\
186 \\
195\end{array}$ & $\begin{array}{c}g m s . \\
1.854 \\
1.860\end{array}$ & $\begin{array}{l}1.896 \\
1.947\end{array}$ & $\begin{array}{l}\text { per cent } \\
-2 \\
-4\end{array}$ \\
\hline
\end{tabular}

So far as the tabular values are concerned, the hybrids with pigmented coats give slightly heavier brain weights than those with non-pigmented coats. However owing to a somewhat greater mortality among the pigmented rats, it is possible that those which died previous to the examination might have been physically inferior individuals which possessed smaller: brains. Even as it stands the difference of 2 per cent is certainly not high enough to be significant when the great individual variability in the brain weights in these hybrids is taken into account. I am thus inclined to believe that there is no definite correlation between the brain weights and the characters of the coat under these conditions.

\section{REMARKS}

As has been stated, the brain weight character appears to blend in inheritance. In this respect the brain weight behaves like body size - weight and length-as well as such characters as ear length and skeletal dimensions in the rabbits studied by Castle and his collaborators ('09).

It has been found by several investigators that in many cases of blended inheritance the characters under consideration show a greater degree of variability in the second filial generation $\left(\mathrm{F}_{2}\right)$ than in the first filial generation $\left(F_{1}\right)$. This greater variability in the $F_{2}$ has been regarded by a number of investigators (see 
Castle, '11) as an indication of the segregation of the character without dominance. My own data are not sufficient for the full discussion of this question and furthermore the material itself is not ideal for the purpose, owing to the probable influence of domestication on the Norway factor. However, so far as my present data show, the degree of variability in the first and second filial generations is practically identical. We find the coefficient of variation of brain weight for $F_{1}$ to be $8.603 \pm 0.396$ while that for $\mathrm{F}_{2}$ is $8.774=0.343$.

It is desirable in this connection to state clearly the difficulties which at present prevent us from reaching a definite conclusion. These difficulties are the following:

a) The wild Norway rats when kept under captivity are furnished with a presumably unaccustomed diet. Since in many animals domestication apparently alters the normal relation between the body size and brain weight (see Darwin, '83 and Lapicque and Girard, '07) the probable effect of captivity on the Norway rats as to their brain weights should be taken into consideration. If the Norways were thus losing in relative brain weight the influence of the Norway factor might be diminished.

b) The brain weight varies with the body size in the rats (see Donaldson, '08, and Donaldson and Hatai, '11). It is therefore possible that any factors which alter the normal growth of the body size may also alter the relative brain weights or even the brain weights may suffer quite independently of the body size.

In spite of these possible sources of error it is to be noted first that the mean brain weights in the $F_{1}$ and $F_{2}$ generations are well above those for the albino parents, showing that some factor was at work to raise the brain weight above that characteristic for the Albinos, and that there is no trace of segregation in the $\mathrm{F}_{2}$ generation.

The above statements have been added here to show the possible precautions to be observed while interpreting the results given in the present paper.

I am however confident that the rats examined here were free from all gross abnormalities and furthermore it is my impression 
that, provided the dietary factor was properly adjusted to the animal, the Norway rats may not have suffored any considerable physical alteration during the short period of captivity (two years or more).

One peculiar phenomenon appearing in the present study was that the range of variability in the brain weights for any given body length was noticeably greater in the hybrids than when either the Norway or albino rats alone were treated. Whether this wide range of brain weight distribution is characteristic for the hybrids in general, or whether it was due to the effects of captivity (including the dietary factor) on normal growth of the brain in weight is difficult to decide. We must await further observations.

\section{CONCLUSIONS}

Despite the fact of the several difficulties already mentioned we may draw the following conclusions:

1) The hybrid offspring $F_{1}$ and $F_{2}$ from Norways $\times$ Albinos possess brain weights which are intermediate between the brain weights given by the norway and albino parents respectively.

2) The frequency distribution of the brain weights in $F_{1}$ and $\mathrm{F}_{2}$ is symmetrical round the mean brain weight, and is closely represented by the normal probability curve. There is no eridence of segregation.

3) It appears that there is no definite correlation between the size of the brain and the character of coat color; that is, the pigmented hybrid rats possess brain weights similar to those of the non-pigmented hybrid rats. 


\section{LITERATURE CITED}

Bateson, W. 1909 Mendel's principles of heredity. Univ. Press. Cambridge. Also G. P. Putnam's Sons, New York, 393 pp.

Castle, W. E. 1909 Studies of inheritance in rabbits. Carnegie Inst. of Wash., no. 114, pp. 1-10.

1911 Heredity in relation to evolution and animal breeding. D. Appleton \& Co., New York and London, $184 \mathrm{pp}$.

Darwin, C. 1883 Variations of animals and plants under domestication 2nd ed. D. Appleton \& Co., New York and London.

Doxamson, H. H. 1908 A comparison of the albino rat with man in respect to the growth of the brain and of the spinal cord. J. Comp. Neur., vol. 18 , pp. $345-390$.

IONat.dan, H. H. and Hatai, S. 1911 A comparison of the Norway rat with the albino rat in respect to body length, brain weight, spinal cord weight and percentage of water in both the brain and the spinal cord. J. Comp. Neur, vol. 21, pp. 417-458.

HATA, S. 1907 On the zoological position of the albino rat. Biol. Bull., vol. 12 , pp. $266-273$.

1911 The Mendelian ratio and blended inheritance. Amer. Nat., vol. 45, pp. 99-106.

Lapicque, I. and Girard, P. 1907 Sur le poids de l'éncéphale chez les animaux domestiques. Compt. rend. Soc. de Biol., vol. 62, p. 1015. 